\title{
Restoring the rare forb Erodium macrophyllum to exotic grassland in southern California
}

\author{
Ian G. Gillespie, Edith B. Allen* \\ Department of Botany and Plant Sciences and Center for Conservation Biology, University of California, Riverside, \\ California 92507-0124, USA
}

\begin{abstract}
Erodium macrophyllum is a rare annual forb that was once widespread in California, but has become largely restricted to clay soil outcrops. An effort was made to restore it to a soil where it was once likely abundant. This soil is now dominated by exotic annual grasses and forbs from the Mediterranean that grow in patches with native forbs. To determine whether there is a competitive hierarchy of E. macrophyllum with the dominant matrix species, we examined establishment and seed production of E. macrophyllum in patches of forbs and grasses in a southern California exotic grassland over 3 yr. We sowed seeds of E. macrophyllum into patches where the dominant species was either Amsinckia menziesii (native forb), Erodium brachycarpum (exotic forb) or Bromus spp. (exotic grasses) and into adjacent manually weeded control plots. All 3 competitors negatively impacted E. macrophyllum seed production, but seldom affected seedling establishment. Although we expected that a native forb would be most compatible with E. macrophyllum, A. menziesii in fact had the most negative effect or was equivalent to E. brachycarpum, and Bromus spp. had the least negative effect. Bromus plants had the lowest density of the 3 matrix species, the lowest rate of recolonization following removal, and grew in soil with the highest levels of extractable $\mathrm{N}$ and $\mathrm{P}$. In this case, the competitive hierarchy was confounded by soil nutrients, so that establishment of E. macrophyllum was greatest in patches of Bromus. However, both native and exotic competitors reduced $E$. macrophyllum establishment, so weeding all known species of competitors will be needed to increase chances of seed production and promote restoration of this rare annual forb.
\end{abstract}

KEY WORDS: Erodium macrophyllum • Competitive hierarchy · Fecundity · Invasive grasses • Invasive forbs $\cdot$ Rare forb

\section{INTRODUCTION}

Competition by invasive species has reduced the abundance of native plant species in many grasslands of the world (Mack 1989, Rose et al. 2004, Seabloom et al. 2006, Isermann et al. 2007) and is a major obstacle to restoration of these species (Nelson \& Allen 1993, Dyer \& Rice 1997, Eliason \& Allen 1997, Tikka Paivi et al. 2001). The rare annual forb Erodium macrophyllum was once widespread across California (Gray 1876), and is now restricted primarily to clay soil outcrops (Gillespie 2005). California grasslands have been invaded by Mediterranean annual grasses and forbs in a broad range of soil types (Heady 1990, Minnich 2008) that may currently restrict the distribution of E. macro- phyllum. A greenhouse study showed that E. macrophyllum has faster growth rates in widespread loamy and sandy soils than clay soil, suggesting that soil is not the limiting factor in its current restricted distribution (Gillespie \& Allen 2006). An experiment was done to introduce E. macrophyllum into a widespread soil type that was likely within its range of habitats in the recent past, but is now heavily invaded by Mediterranean annuals.

Although California was historically known for extensive fields dominated by native forbs (Schiffman 2000, Minnich 2008), few restoration studies have explicitly focused on forbs. In one example, the endangered native annual Amsinckia grandiflora competed poorly with 
exotic grasses (Pavlik et al. 1993), but established well in a matrix of native grasses and forbs (Carlsen et al. 2000). The choice of sites and species to target for restoration must be undertaken with an understanding of the relationships between invasive and native species. One-time treatments such as fire, mowing and weeding may alter community composition enough to allow reestablishment of desired species, but their effects are often short-lived because the invasive species return in abundance after a few years (Dyer et al. 1996, Allen et al. 2005, DiTomaso et al. 2006).

Our approach to establishing Erodium macrophyllum was to select different competitive backgrounds so the rare species would be in a matrix of other native species or invasive species. Revegetating the entire site to alter the competitive background is difficult (Carlsen et al. 2000), so we took advantage of natural patches of native species. Dominant species can vary temporally and spatially, especially in annual vegetation (Heady 1958). These dominants may form competitive hierarchies with different abilities to exclude the species being restored (Keddy 1990, Shipley \& Keddy 1994, Connolly 1997, Keddy et al. 2000). In annual grasslands in southern California the dominant species are often Amsinckia menziesii (native forb; Menzie's fiddleneck), Erodium spp. (exotic forbs; filaree) and Bromus spp. (exotic grass; brome grasses). Restoration work in southern California grasslands has resulted in areas where the dominant species have shifted from exotic grasses to exotic forbs (Allen et al. 2005, Cox \& Allen 2008). If the competitive relationships between the target restoration species and the dominant exotic and native species were understood, then restoration efforts could be appropriately aimed at seeding with natives in specific areas where competitive relationships are reduced.

In this study we used a competitive hierarchy approach to restore Erodium macrophyllum to an exotic grassland. In a prior study using fire to control exotic grasses, E. macrophyllum was more abundant in a matrix of exotic E. botrys plus the native perennial Nassella pulchra (purple needle grass) than in a matrix of exotic grasses, also suggesting a competitive hierarchy dominated by exotic grasses (Gillespie \& Allen 2004). We hypothesized that the competitive hierarchy for establishment of E. macrophyllum would range from exotic grasses as the most competitive, to exotic forbs as the next most competitive, and native forbs as compatible with establishing a rare species (Nelson \& Allen 1993, Dyer \& Rice 1997, Eliason \& Allen 1997, Tikka Paivi et al. 2001, Gillespie \& Allen 2004, Allen et al. 2005, Cox \& Allen 2008). We tested the hypothesis by seeding E. macrophyllum in weeded and control patches of the 3 matrix species and followed establishment and fecundity over $3 \mathrm{yr}$.

\section{MATERIALS AND METHODS}

Study area. The study took place in Crown Valley at the Western Riverside County Multi-Species Reserve, California, USA $\left(33.6558^{\circ} \mathrm{N}, 116.9986^{\circ} \mathrm{W} ; 640 \mathrm{~m}^{2}\right)$. Crown Valley is relatively flat, comprised mainly of exotic annual species with sparse native forbs, and was cropped with annual grains until abandonment approximately 20 years ago. Sparse shrubs of Ericameria palmerii have colonized the valley floor, but the most common species are exotic annual grasses (Bromus madritensis ssp. rubens and $B$. diandrus), the exotic forb Erodium brachycarpum, and the native forb Amsinckia menziesii. These species often form patches where each one is almost completely dominant, and each was chosen as a matrix species to compare competitive responses with seeded E. macrophyllum. Species nomenclature follows Hickman (1993).

The Reserve has a Mediterranean-type climate with most of the rainfall occurring between November and April, with an annual average of $260 \mathrm{~mm}$. The winter growing season is generally cool and mild while summers are dry and hot. After the first late-fall or winter rains of the season the vegetation at the Reserve is transformed, as the dormant seeds in the soil germinate and turn the valleys green with the annual vegetation distinctive of California exotic grasslands. During the $3 \mathrm{yr}$ of the study, growing season precipitation was $180 \mathrm{~mm}$ in 2000 to 2001 (July 1 to June 30), $75 \mathrm{~mm}$ in 2001 to 2002, and $305 \mathrm{~mm}$ in 2002 to 2003.

Erodium macrophyllum does not occur naturally in Crown Valley, which had likely been farmed for almost 100 yr prior to abandonment (Allen et al. 2005), but does occur about $1 \mathrm{~km}$ away in clay soil outcrops on Bachelor Mountain (Gillespie 2005). The soil in Crown Valley is a sandy loam mollisol derived from granitic parent material. Most of the valleys of the region have been historically dry-farmed with annual grains or converted to annual pasture grasses, so this is typical of the kind of site and soil type where restoration would occur.

Experimental design. We used a $2 \times 3$ factorial block design replicated 5 times to assess the effects of different matrix species on Erodium macrophyllum. For each of the 5 blocks, we found an area in Crown Valley that had patches where Bromus spp., E. brachycarpum, or Amsinckia menziesii were dominant, so that each block contained plots with all 3 matrix species. A matrix species was considered dominant in a patch if it had $>85 \%$ relative cover. In each of these relatively uniform patches we set up paired plots, one of which received a weeding treatment and the other was left unmanipulated as a control (5 blocks $\times 3$ matrix species $\times 2$ weeding treatments $=30$ plots $)$. Each plot was $1.0 \times 0.5 \mathrm{~m}$ and approximately $1 \mathrm{~m}$ away 
from its corresponding weeded or non-weeded plot. For the weeding treatment all species, native and exotic, were manually removed as seedlings except for E. macrophyllum. Weeding was also done in a $20 \mathrm{~cm}$ unsampled edge around each plot. These plots were continually weeded in fall of 2000 and winter 2001, but they were not weeded again in the 2001 to 2002 or 2002 to 2003 growing seasons so that we could assess recolonization of the matrix species.

In fall of 2000, before the onset of winter rains, we hand broadcast approximately 200 seeds of Erodium macrophyllum into each plot. As seedlings emerged in each plot, they were marked with a wooden toothpick and monitored every 1 to $2 \mathrm{wk}$. Because germination and seed production of E. macrophyllum were low during the 2000 to 2001 growing season (a mean of only 1 plant per plot survived initial seedling establishment of the 200 seeds in Amsinckia menziesii matrix plots), we hand sowed and buried to $1 \mathrm{~mm}$ depth 12 additional seeds into each plot in an equally spaced grid in fall of 2001 to ensure sufficient plants during the 2002 and 2003 spring growing seasons. The nocturnal seed herbivore Stephen's kangaroo rat Dipodomys stephensii and other herbivorous small mammals occur in Crown Valley. In case seed herbivory was the cause of low germination during the 2001 growing season, seeds were buried so they would more likely escape herbivory. The potential for less seed herbivory also allowed us to add fewer seeds in fall 2001.

Data collection. We monitored all germinated plants of Erodium macrophyllum for 3 consecutive growing seasons between fall 2000 and spring 2003. Seeds typically germinated with the first rains of the season in October to December, depending on the year. Seedlings were counted in January 2001 and 2003. At the end of each growing season (April to May) we counted the number of fruits produced on each $E$. macrophyllum plant as an assessment of fecundity. However, because of an unprecedented seasonal drought during the 2001 to 2002 growing season, no E. macrophyllum plants lived to reproduce. During April to May of the 2000 to 2001 and 2002 to 2003 growing seasons we also estimated the percent cover of matrix plants (exotic grass, exotic forb and native forb) and $E$. macrophyllum in each plot. Again, because of the drought during the 2001to 2002 growing season, we did not estimate percent cover of the different matrix groups because plant cover was very low and almost all species were dead in April. Percent cover of matrix species was estimated to the nearest $1 \%$ by placing a gridded frame over each plot. Estimates for percent cover were always made by the same person to reduce subjective error.

During January of 2001 and 2003 we measured Erodium macrophyllum neighbor density and overall plot density. Neighbor density was measured in January by randomly selecting 155 E. macrophyllum seedlings, placing a $16 \mathrm{~cm}^{2}$ mini-frame around the center of 1 E. macrophyllum seedling and counting the density of each neighbor species. E. macrophyllum seedlings were approximately 2 to $3 \mathrm{~cm}$ in diameter when we counted neighbor density. For all $155 E$. macrophyllum seedlings, the neighbors were always Amsinckia menziesii, Bromus spp. and/or E. brachycarpum.

Overall plot density was measured again in April of 2003 by randomly placing a $36 \mathrm{~cm}^{2}$ frame (plants were larger, requiring a larger frame) in each plot and counting the number of rooted plants within the frame. At this time, most of the plants were reproducing or at least beginning to bolt. For grass density, individual plants were counted, not tillers.

In February of 2003 we collected soil samples from each of the plots to compare soil nutrients in patches dominated by different matrix species. Soil was collected from the upper $10 \mathrm{~cm}$ of the soil profile from near the center of each plot while doing minimal harm to any plants. Soils were analyzed for waterextractable nitrate $\left(\mathrm{NO}_{3}{ }^{-}\right)$, bicarbonate-extractable phosphorus (P), and organic matter by combustion at the Analytical Laboratory of the Division of Agriculture and Natural Resources, University of California, Davis, California.

Statistical analyses. We used a 2-way ANOVA (analysis of variance) with 2 levels of competition and 3 levels of matrix species to assess the treatment effects and their interaction on percent cover of different species, Erodium macrophyllum fecundity and soil nutrient characteristics. For E. macrophyllum fecundity we used the mean fruits per plant as the dependent variable. Analyses were done using StatView and JMP (SAS Institute). Means and standard errors (SE) are reported throughout and $\mathrm{p}<0.05$ was considered significant. Mean separations were done using the least significant difference $\left(\mathrm{LSD}_{0.05}\right)$.

\section{RESULTS}

Density of Erodium macrophyllum in January 2001 was significantly greater in the plots where Bromus spp. was the matrix species than Amsinckia menziesii or E. brachycarpum ( $\mathrm{p}=0.048$; Table 1$)$. By April of 2001 the density of surviving E. macrophyllum had declined almost to 0 , as this was a dry spring, although prior to April plants survived to maturity, so fruit set could be assessed on senescent plants. In January 2002 the density of E. macrophyllum was also greatest in Bromus plots; establishment was greater in nonweeded than weeded plots within each matrix species 
Table 1. Erodium macrophyllum. Density of rare forb with different background (matrix) species under 2 treatments, weeded (W) and non-weeded (NW), for the 2001, 2002, and 2003 growing seasons. Letter superscripts (based on the least significant difference, $\mathrm{LSD}_{0.05}$ ) indicate significant differences in E. macrophyllum densities among matrix species and weeding treatments in 2001 and 2002, but there were no significant differences in 2003

\begin{tabular}{|lccccc|}
\hline \multirow{2}{*}{ Matrix species } & \multirow{2}{*}{ Treatment } & \multicolumn{4}{c|}{ Density (plants ${ }^{-2}$ ) \pm SE } \\
\cline { 3 - 6 } & & Jan 2001 & Jan 2002 & Jan 2003 & Apr 2003 \\
\hline Bromus spp. & W & $6.0^{\mathrm{a}} \pm 2.1$ & $21.2^{\mathrm{b}} \pm 18.3$ & $18.8 \pm 2.1$ & $12.0 \pm 5.0$ \\
Bromus spp. & NW & $6.8^{\mathrm{a}} \pm 2.1$ & $35.2^{\mathrm{c}} \pm 12.8$ & $20.4 \pm 7.7$ & $13.3 \pm 4.8$ \\
Amsinckia menziesii & W & $2.4^{\mathrm{b}} \pm 2.9$ & $8^{\mathrm{a}} \pm 9.6$ & $16.0 \pm 1.6$ & $14.0 \pm 7.0$ \\
Amsinckia menziesii & NW & $3.2^{\mathrm{b}} \pm 0.8$ & $25.6^{\mathrm{b}} \pm 11.1$ & $10.4 \pm 0.8$ & $15.0 \pm 2.6$ \\
Erodium brachycarpum & W & $3.2^{\mathrm{b}} \pm 1.6$ & $10.8^{\mathrm{a}} \pm 12.6$ & $17.6 \pm 1.9$ & $10.0 \pm 0.8$ \\
Erodium brachycarpum & NW & $2.8^{\mathrm{b}} \pm 1.5$ & $21.6^{\mathrm{b}} \pm 12.9$ & $11.6 \pm 3.5$ & $9.0 \pm 2.7$ \\
& & & & & \\
\hline
\end{tabular}

treatment, suggesting an initial beneficial effect of matrix plant cover on establishment in this dry year. However, the density of E. macrophyllum was also 0 in April 2002, and no plants reached maturity because of the drought. In 2003 there were no significant differ-

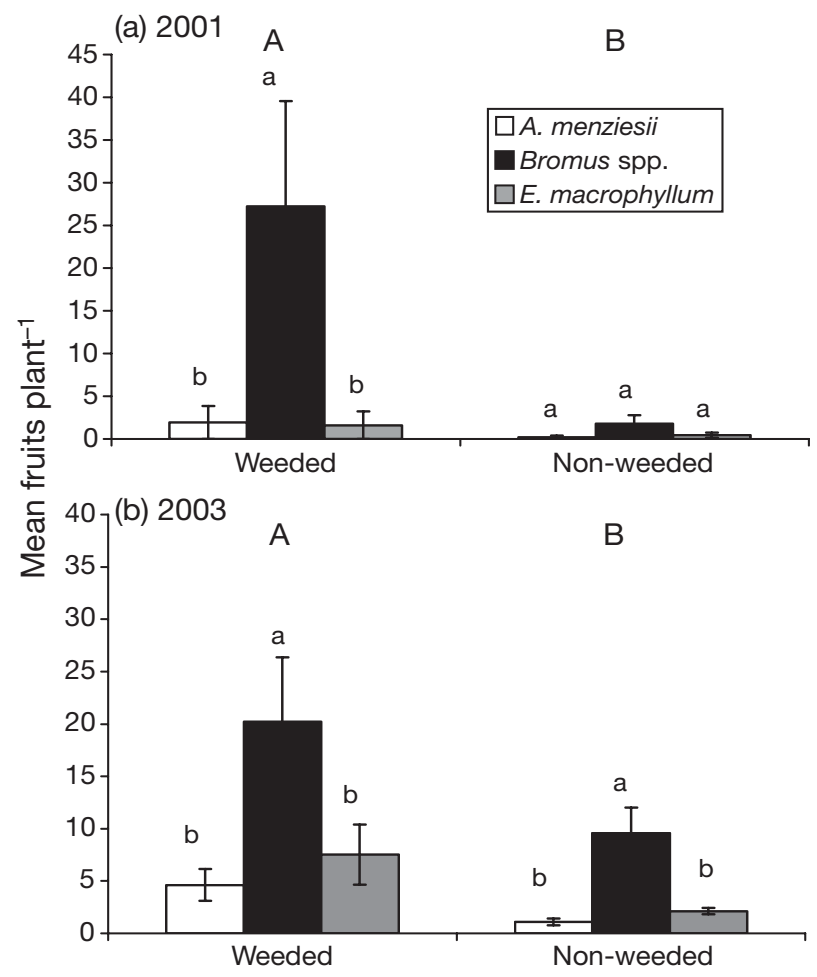

Fig. 1. Erodium macrophyllum. Fecundity of the rare forb growing in weeded and non-weeded plots and with 3 different matrix competitors, Amsinckia menziesii (native forb), Bromus spp. (exotic grass) and E. brachycarpum (exotic forb) in (a) 2001 and (b) 2003. There are no data for spring of 2002 because it was a drought year. Different capital letters indicate a significant difference between weeding treatments with species pooled $(\mathrm{p}<0.05)$; different lowercase letters indicate a significant difference between species within treatments. Values are means $\pm \mathrm{SE}$ ences in E. macrophyllum densities among matrix species treatments within either of the 2 sample dates (Table 1). The E. macrophyllum plants that established in the 2003 growing season could have come from seeds of the initial seeding in fall 2000, seeds produced during the first year, or seeds from hand sowing in fall 2001.

Fecundity of Erodium macrophyllum had a more pronounced response to matrix species than did density. During 2001 E. macrophyllum plants growing in weeded plots produced more fruit than in the nonweeded plots (Fig. 1a). For weeded plots, E. macrophyllum had the greatest fecundity in the plots dominated by Bromus spp. (Fig. 1a). During 2003, E. macrophyllum plants growing in the weeded plots also had greater fecundity than in non-weeded plots (Fig. 1b), even though weeding had only been done once 2 yr earlier. There was also a matrix species effect, where E. macrophyllum plants growing in Bromus spp. plots had the greatest fecundity (Fig. 1b).

Plots that were weeded in fall of 2000 were not weeded again in subsequent years, so any plants growing in them represented natural re-establishment following removal of all species (except Erodium macrophyllum). Cover of species groups (exotic grasses, exotic forbs, native forbs) in weeded plots was less than that for the same species group in nonweeded plots, although total cover was comparable among the weeding treatments (Fig. 2). Cover of Bromus spp. was consistently lower in the weeded plots indicating low recovery by Bromus spp. and more rapid invasion by Amsinckia menziesii and E. brachycarpum. The cover of Bromus spp. was approximately equally divided among the 2 species present, $B$. rubens and $B$. diandrus. The native forb group included primarily the annual forb $A$. menziesii, with a few percent cover of Calandrinia ciliata and Emmenanthe penduliflora. The exotic forb species were primarily the annual E. brachycarpum, and lesser cover of Medicago polymorpha and Sisymbrium 


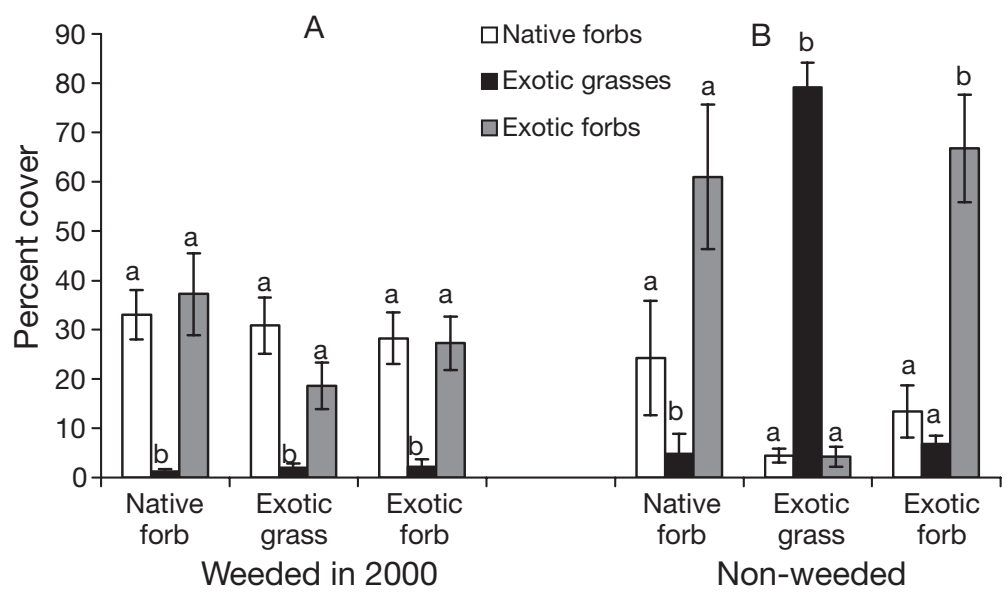

Fig. 2. Amsinckia menziesii, Bromus spp., and Erodium branchycarpum. Percent cover of 3 species groups (native forbs, exotic forbs and exotic grasses) in 2003 growing in plots that were weeded in 2000, and in nonweeded plots. Percent cover was measured for each weeded and nonweeded plot in each of the 3 matrix species patche. Different capital letters indicate a significant difference between weeding treatments with species pooled $(\mathrm{p}<0.05)$; different lowercase letters indicate a significant difference between species within treatments. Values are means $\pm \mathrm{SE}$
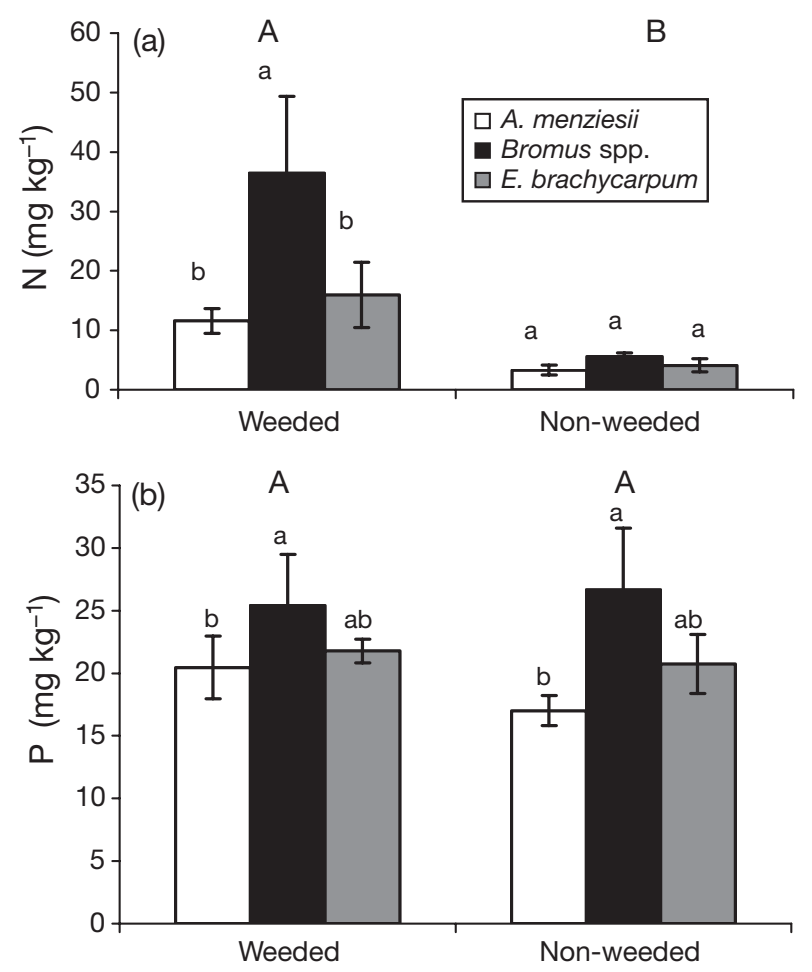

Fig. 3. Soil extractable nutrients, (a) nitrate and (b) phosphorus, in Crown Valley for weeded and non-weeded plots in a full factorial design with 3 different background matrix species treatments (Amsinckia menziesii, Bromus spp. and Erodium brachycarpum). Different capital letters indicate a significant difference between weeding treatments with species pooled $(\mathrm{p}<0.05)$; different lowercase letters indicate a significant difference between species within treatments. Values are means $\pm \mathrm{SE}$ irio, and the exotic grasses were $B$. diandrus and B. rubens.

In 2003 the weeded plots (last weeded in 2001) were less dense than non-weeded plots $\left(F=40.73_{1,24}, \mathrm{p}<0.0001\right)$. Weeded plots had 472 plants $\mathrm{m}^{-2}$ and non-weeded had 1500 plants $\mathrm{m}^{-2}$ averaged over all species present. The non-weeded Bromus spp. plots (444 Bromus spp. plants $\mathrm{m}^{-2}$ ) were less dense than either the Amsinckia menziesii (1250 plants $\mathrm{m}^{-2}$ ) or Erodium brachycarpum plots (1222 plants $\left.\mathrm{m}^{-2}\right)(F=$ $\left.9.83_{2,24}, \mathrm{p}=0.0008\right)$.

There was both a weeding effect and a weeding $\times$ matrix species effect $(\mathrm{p}=$ 0.001 ) on nitrate, and a matrix species effect on phosphorus (Fig. 3). Weeded Bromus spp. plots had greater soil nitrate than the other matrix species treatments (Fig. 3a). There was no difference in phosphorus between the weeding treatments, but there was higher phosphorus in plots dominated by Bromus spp. (Fig. 3b). There was no significant difference in percent soil organic matter among any of the treatments (mean \% organic matter $=1.56 \pm 0.52$ ).

\section{DISCUSSION}

The invasion of California by Mediterranean annuals occurred early, before botanical records were kept, so attempts to restore the vegetation are often done in the absence of knowledge of the original vegetation (Minnich 2008). We initiated restoration to understand the interactions of Erodium macrophyllum with dominant native and invasive species. As hypothesized, the native Amsinckia menziesii did not provide a matrix of reduced competition compared to the exotic species. In fact, A. menziesii is a widespread native that has achieved weedy status in some areas under domestic grazing (Heady 1958, Pantone et al. 1995), and its present-day dominance may not be reflective of the presettlement vegetation of California. E. macrophyllum may never have been abundant in stands of A. menziesii, but rather persisted historically in areas of unknown native species composition. The clay outcrops where it currently occurs have sparse cover of both native and exotic species (Gillespie 2005).

Exotic grasses have been the focus of restoration studies because of their dominance (e.g. Dyer \& Rice 1997, Eliason \& Allen 1997, Hamilton et al. 1999), but our results showed that the impact of Bromus spp. on Erodium macrophyllum was not as great as that of either matrix forb species, Amsinckia menziesii or E. 
brachycarpum. This suggests that the congener E. brachycarpum and other exotic species of Erodium may also be important in the displacement of E. macrophyllum throughout California. The Bromus plots provided less competitive environments than the other matrix species plots, but $B$. rubens may not necessarily be inferior in one-on-one competition (Yoshida \& Allen 2004). Furthermore, applying a restoration technique that reduced exotic grass was not as effective as hoped for, as it resulted in increased density and cover of exotic forbs, primarily $E$. brachycarpum. Other attempts to control dominant invasive species have similarly resulted in an increase in exotic or undesired species, so this was not an unexpected result (Cione et al. 2002, Allen et al. 2005, Hulme \& Bremner 2005, Cox \& Allen 2008).

Bromus spp. did not impact Erodium macrophyllum fecundity as severely as the other matrix species, both because of lower cover and density of Bromus spp. and because of elevated soil nitrate and phosphorus in Bromus plots. It is not apparent whether Bromus spp. grew in these patches because it requires soil of higher nitrate and phosphorus, uses less nitrate and phosphorus, or promotes greater nitrate and phosphorus mineralization. A number of invasive plant species are known to have feedbacks on the soils they colonize by causing changes in soil chemical and biological properties (Ehrenfeld 2003). For instance, B. tectorum (Blank \& Young 2004) also has elevated soil nitrate because of increased nitrate mineralization, so higher rates of mineralization are possible for the 2 species of Bromus examined in this study. The higher soil nitrate after removal of Bromus could be a result of reduced nitrate uptake by the absence of a dominant species, or elevated mineralization from the roots that were left after shoots were removed. We removed aboveground material to minimize nutrient effects from decomposing plant material, but such effects cannot be avoided entirely in removal experiments because roots remain. In contrast, removal of the 2 forb species did not cause a change in soil nitrate.

The competitive hierarchy was reversed in another study on establishment of Erodium macrophyllum, which established poorly in Bromus spp.-dominated stands, but had greater density following fire where the dominant matrix species was the exotic E. botrys (Gillespie \& Allen 2004). However, the use of fire was a critical difference in this study, as the fire treatment may have released mineral nitrate (DiTomaso et al. 2006) in plots that were then colonized by high-density E. botrys. This suggests that elevated soil nitrate and/or phosphorus are likely responsible for the improved performance of E. macrophyllum in Bromus plots, rather than differential competitive ability with Bromus spp. compared to the other matrix species.
Thus, soil nutrients may be more important in determining the competitive hierarchy of E. macrophyllum with the matrix species than their intrinsic competitive characteristics.

Competitive abilities can change with shifts in resources and disturbance (Tilman 1982, Suding \& Goldberg 2001). The clay soils on which remnant natural populations of Erodium macrophyllum occur are low in nitrate and phosphorus levels compared to the Crown Valley soils (Gillespie 2005). Greenhouse experiments showed that E. macrophyllum grew better in soils with higher concentrations of nitrate and phosphorus (Gillespie \& Allen 2006). But this does not necessarily indicate its competitive ability; the matrix species may be even more responsive than $E$. macrophyllum to higher nutrients and better soil texture, as they showed by their dominance at the research site. Or conversely, the matrix species may be poorer competitors in low productivity soils where $E$. macrophyllum is successful. This hypothesis is in agreement with an experiment by Keddy et al. (2000) in which competitive ability of several species increased with soil productivity, while others declined. Soil nutrition is an important factor when assessing competitive hierarchy.

Recolonization of Bromus spp. following weeding was surprisingly slow during the 3 years, and may be related to the altered soil microsites and requirements for Bromus establishment following weeding and litter removal. Weeded plots may have been more rapidly recolonized by native and exotic forbs relative to Bromus spp. because some of these species have increased germination on exposed soils (Rice 1985). That is, non-Bromus plots may have high density and cover of native and exotic forbs because they preferentially establish where there is not a dense buildup of grass litter. The increase in native forbs after weeding plots, even after $3 \mathrm{yr}$, shows that without weeding, exotic grasses and forbs suppress native forbs. The slow response of Bromus spp. to reestablish in weeded areas is potentially useful for restoration purposes because this provides a window of time in which native species might establish with reduced competition. This window was up to $5 \mathrm{yr}$ in another experiment in Crown Valley (Allen et al. 2005). While hand weeding large areas is not practical, other restoration methods such as grazing, herbicide, and fire can be used to reduce cover of exotic grasses (Gillespie \& Allen 2004, Allen et al. 2005, DiTomaso et al. 2006).

Restoration of Erodium macrophyllum and other native forbs into these invaded grasslands will be difficult at best. Given the higher levels of soil nitrate and phosphorus under Bromus, seeding E. macrophyllum into patches of Bromus spp. will result in the greatest likelihood of successful establishment, at least in the 
short term observed here, because E. macrophyllum consistently produced more fruits in these plots. Longterm observations will be required to determine whether these newly introduced plants persist in this location and how frequently Bromus spp. and the other matrix species will need to be controlled. Abundance of annual exotic grasses and forbs fluctuate with annual variability in climate, and grasses became especially abundant in Crown Valley during the wet year of 2004 following this study (Allen et al. 2005). In another reintroduction study, the rare native annual Amsinckia grandiflora persisted in restored native grassland but not in exotic grassland (Carlsen et al. 2000), suggesting that continued control of exotic grasses would be needed for persistence of restored native forbs. Thus, the next step for restoration of $E$. macrophyllum or any rare species is to reintroduce the associated native flora and thereby create a more stable community for its persistence. This will be particularly challenging in California because of the absence of information about the original native community composition (Minnich 2008). Understanding the competitive hierarchy of exotic and native species interactions, and how associated changes in soil nutrients interacts with this hierarchy, is an important step toward restoring rare native species.

Acknowledgements. We are especially thankful to the managers of the western Riverside County Multi-Species Reserve for allowing us to conduct this experiment. Funding for this research was provided through grants from the SkinnerShipley Endowment through the College of Natural and Agricultural Resources, University of California, Riverside (UCR), and from the Center for Invasive Plant Management, Montana State University. Hally Andersen and Minh Dang provided tremendous help in the field.

\section{LITERATURE CITED}

Allen EB, Cox RD, Tennant T, Kee SN, Deutschman DH (2005) Landscape restoration in southern California forblands: response of abandoned farmland to invasive annual grass control. Isr J Plant Sci 53:237-245

Blank RR, Young JA (2004) Influence of three weed species on soil nutrient dynamics. Soil Sci 169:385-397

> Carlsen TM, Menke JW, Pavlik BM (2000) Reducing competitive suppression of a rare annual forb by restoring native California perennial grasslands. Restor Ecol 8:18-29

Cione NK, Padgett PE, Allen EB (2002) Restoration of a native shrubland impacted by exotic grasses, frequent fire, and nitrogen deposition in southern California. Restor Ecol 10:376-384

> Connolly J (1997) Substitutive experiments and the evidence for competitive hierarchies in plant communities. Oikos 80:179-182

> Cox RD, Allen EB (2008) Stability of exotic annual grasses following restoration efforts in southern California coastal sage scrub. J Appl Ecol 45:495-504
DiTomaso JM, Brooks ML, Allen EB, Minnich R, Rice PM, Kyser GB (2006) Control of invasive weeds with prescribed burning. Weed Technol 20:535-548

Dyer AR, Rice KJ (1997) Intraspecific and diffuse competition: the response of Nassella pulchra in a California grassland. Ecol Appl 7:484-492

Dyer AR, Fossum HC, Menke JW (1996) Emergence and survival of Nassella pulchra in a California grassland. Madrono 43:316-333

Ehrenfeld JG (2003) Effects of exotic plant invasions on soil nutrient cycling processes. Ecosystems 6:503-523

Eliason SA, Allen EB (1997) Exotic grass competition in suppressing native shrubland re-establishment. Restor Ecol 5:245-255

Gillespie IG (2005) Habitat characteristics and distribution of Erodium macrophyllum (Geraniaceae). Madrono 52: 53-59

Gillespie IG, Allen EB (2004) Fire and competition in a southern California grassland: impacts on the rare forb Erodium macrophyllum. J Appl Ecol 41:643-652

Gillespie IG, Allen EB (2006) Effects of soil and mycorrhizae from native and invaded vegetation on a rare California forb. Appl Soil Ecol 32:6-12

Gray A (1876) Botany of California. Welch, Bigelow, \& Co., University Press, Cambridge

Hamilton JG, Holzapfel C, Mahall BE (1999) Coexistence and interference between a native perennial grass and nonnative annual grasses in California. Oecologia 121:518-526

> Heady HF (1958) Vegetational changes in the California annual type. Ecology 39:402-416

Heady HF (1990) Valley grassland. In: Barbour MG, Major J (eds) Terrestrial vegetation of California. California Native Plant Society, Sacramento, CA, p 491-514

Hickman JC (ed) (1993) The Jepson manual: higher plants of California. University of California Press, Berkeley, CA

> Hulme PE, Bremner ET (2005) Assessing the impact of Impatiens glandulifera on riparian habitats: partitioning diversity components following species removal. J Appl Ecol 43:43-50

Isermann M, Diekmann M, Heemann S (2007) Effects of the expansion by Hippophae rhamnoides on plant species richness in coastal dunes. Appl Veg Sci 10:33-42

Keddy PA (1990) Competitive hierarchies and centrifugal organization in plant communities. In: Grace JB, Tilman D (eds) Perspectives on plant competition. Academic Press, San Diego, CA, p 265-290

> Keddy P, Gaudet C, Fraser LH (2000) Effects of low and high nutrients on the competitive hierarchy of 26 shoreline plants. J Ecol 88:413-423

Mack RN (1989) Temperate grasslands vulnerable to plant invasion: characteristics and consequences. In: Drake JA, Mooney HA (eds) Biological invasions: a global perspective. John Wiley and Sons, New York, p 155-179

Minnich RA (2008) California's fading flowers: lost legacy and biological invasions. University of California Press, Berkeley, CA

> Nelson LL, Allen EB (1993) Restoration of Stipa pulchra grasslands: effects of mycorrhizae and competition from Avena barbata. Restor Ecol 1:40-50

Pantone DJ, Pavlik BM, Kelley RB (1995) The reproductive attributes of an endangered plant as compared to a weedy congener. Biol Conserv 71:305-311

Pavlik BM, Nickrent DL, Howald AM (1993) The recovery of an endangered plant: I. Creating a new population of Amsinckia grandiflora. Conserv Biol 7:510-526

Rice KJ (1985) Responses of Erodium to varying microsites: the role of germination cueing. Ecology 66:1651-1657 
Rose AB, Suisted PA, Frampton CM (2004) Recovery, invasion, and decline over 37 years in a Marlborough shorttussock grassland, New Zealand. NZ J Bot 42:77-87

Schiffman PM (2000) Mammal burrowing, erratic rainfall, and the annual lifestyle in the California prairie: is it time for a paradigm shift? In: Keeley J, Baer-Keeley M, Fotheringham CJ (eds) Interface between ecology and land development in California. US Geological Survey, Los Angeles, CA, p 153-160

Seabloom EW, Williams JW, Slayback D, Stoms DM, Viers JH, Dobson AP (2006) Human impacts, plant invasion, and imperiled plant species in California. Ecol Appl 16: 1338-1350

Shipley B, Keddy PA (1994) Evaluating the evidence for com-

Editorial responsibility: David Roberts,

Richmond, UK petitive hierarchies in plant communities. Oikos 69: 340-345

Suding KN, Goldberg D (2001) Do disturbances alter competitive hierarchies? Mechanisms of change following gap creation. Ecology 82:2133-2149

Tikka Paivi M, Heikkila T, Heiskanen M, Kuitunen M (2001) The role of competition and rarity in the restoration of a dry grassland in Finland. Appl Veg Sci 4:139-146

Tilman D (1982) Resource competition and community structure. Princeton University Press, Princeton, NJ

Yoshida LC, Allen EB (2004) ${ }^{15} \mathrm{~N}$ uptake by mycorrhizal Artemisia californica and the invasive Bromus madritensis of a N-eutrophied shrubland. Biol Fertil Soils 39:243-248

Submitted: September 22, 2007; Accepted: June 2, 2008

Proofs received from author(s): July 24, 2008 